\title{
A Well System to Recover Usable Water from a Freshwater-Saltwater Aquifer in Puerto Rico
}

\section{United States \\ Geological \\ Survey \\ Water-Supply \\ Paper 2328}

Prepared in

cooperation with

Water Resources

Research Institute,

University of

Puerto Rico

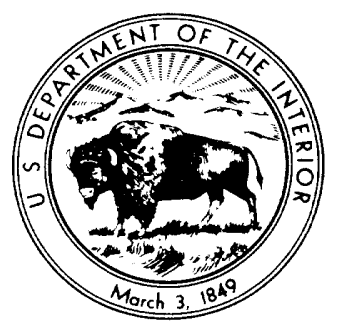




\title{
A Well System to Recover Usable Water from a Freshwater-Saltwater Aquifer in Puerto Rico
}

\author{
By ALLEN L. ZACK
}

Prepared in cooperation with

Water Resources Research Institute,

University of Puerto Rico 
DEPARTMENT OF THE INTERIOR

DONALD PAUL HODEL, Secretary

U.S. GEOLOGICAL SURVEY

Dallas L. Peck, Director

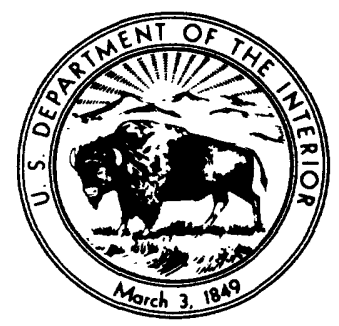

For sale by the

Books and Open-File Reports Section

U.S. Geological Survey

Federal Center, Box 25425

Denver, CO 80225

Library of Congress Cataloging-in-Publication Data

Zack, Allen L.

A well system to recover usable water from a freshwater-

saltwater aquifer in Puerto Rico.

U.S. Geological Survey Water-Supply Paper 2328

Bibliography

Supt. of Docs. No.: I 19.13:2328

1. Water-supply-Puerto Rico. 2. Water, Underground-

Puerto Rico. 1. University of Puerto Rico (Mayagüez

Campus). Water Resources Research Institute. II. Title.

III. Series.

TD223.P9Z33 1988

$628.1^{\prime} 14$

$87-600408$ 


\section{CONTENTS}

Abstract 1

Introduction $\mathbf{1}$

Background 1

Purpose and scope 1

Study area: location and hydrologic setting 1

Theory and operation of recovery wells 2

Hydraulic theory of vertical saltwater movement $\mathbf{3}$

Scavenger/production well systems $\mathbf{5}$

Description of demonstration well $\mathbf{5}$

Vertical movement of saltwater at well site $\mathbf{5}$

Determination of optimal freshwater discharge from production well 7

Field testing the scavenger/production well system 9

Application of design to other wells and aquifers 11

Summary and conclusions 13

Selected references $\mathbf{1 5}$

\section{FIGURES}

1. Map showing location of La Trocha well, Puerto Rico 2

2. Schematic diagrams of equipotential lines and upward movement of saltwater in four well conditions 3

3. Schematic diagram showing equipotential lines and saltwater response to ground-water withdrawals from wells in three aquifers having vertical differences in horizontal hydraulic conductivity 4

4-13. Graphs showing:

4. Depth/specific-conductance profiles at various times in La Trocha well as nearby USGS-1 well is pumped 6

5. Examples of time/specific-conductance profiles of water withdrawn from La Trocha well at various pumping rates 7

6. Static and pumping specific-conductance profiles and flowmeter results, La Trocha well $\mathbf{8}$

7. Chloride concentration and specific conductance of water withdrawn from La Trocha well at various pumping rates $\mathbf{8}$

8. Chloride load of water withdrawn from La Trocha well at various pumping rates, and corresponding asymptotes for freshest and saltiest water attainable 9

9. Examples of time/specific-conductance profiles for two scavenger/ production well couples at different pumping rates $\mathbf{1 0}$

10. Chloride concentration of water withdrawn from La Trocha well by different pump rates $\mathbf{1 0}$

11. Chloride load of water withdrawn from La Trocha well by different pump rates $\mathbf{1 2}$

12. Chloride load of water withdrawn from La Trocha well by production well and scavenger well pumping simultaneously at various rates 13

13. Chloride concentration of water withdrawn from La Trocha well by production well and scavenger well pumping simultaneously at various rates 14 


\section{Conversion Factors}

For the convenience of readers who prefer metric (International System) units rather than the inchpound units used in this report, the following factors may be used:

\begin{tabular}{|c|c|c|}
\hline Multiply & By & To obtain \\
\hline inch (in.) & 25.4 & millimeter (mm) \\
\hline foot $(\mathrm{ft})$ & 0.3048 & meter (m) \\
\hline gallon per minute (gal/min) & 0.06308 & liter per second $(\mathrm{L} / \mathrm{s})$ \\
\hline gallon (gal) & 3.785 & liter $(\mathrm{L})$ \\
\hline ounce, avoirdupois (oz) & 28.35 & gram $(\mathrm{g})$ \\
\hline pound, avoirdupois (lb) & 453.6 & gram $(\mathrm{g})$ \\
\hline $\begin{array}{l}\text { micromhos per centimeter, } \\
\text { at } 25 \text { degrees Celsius } \\
\left(\mu \mathrm{mho} / \mathrm{cm} \text { at } 25^{\circ} \mathrm{C}\right)\end{array}$ & 1.000 & $\begin{array}{l}\text { microsiemens per centimeter } \\
\text { at } 25 \text { degrees Celsius } \\
\left(\mu \mathrm{S} / \mathrm{cm} \text { at } 25^{\circ} \mathrm{C}\right)\end{array}$ \\
\hline $\begin{array}{l}\text { gallon per minute per foot } \\
{[(\mathrm{gal} / \mathrm{min}) / \mathrm{ft}]}\end{array}$ & 0.2070 & $\begin{array}{l}\text { liter per second per meter } \\
{[(\mathrm{L} / \mathrm{s}) / \mathrm{m}]}\end{array}$ \\
\hline square feet per day $\left(\mathrm{ft}^{2} / \mathrm{d}\right)$ & 0.0929 & square meters per day $\left(\mathrm{m}^{2} / \mathrm{d}\right)$ \\
\hline
\end{tabular}




\title{
A Well System to Recover Usable Water from a Freshwater-Saltwater Aquifer in Puerto Rico
}

\author{
By Allen L. Zack
}

\begin{abstract}
Aquifers in coastal areas of Puerto Rico commonly contain limited quantities of freshwater that occur as a thin layer at the surface of the water table. Many wells have been abandoned because well screens were inadvertently placed in saltwater parts of the aquifer.

A scavenger/production well couple that can be installed in an abandoned well, screened in both freshwater and saltwater parts of the aquifer, provides an effective method for extracting freshwater from the well. Withdrawal of a sufficient quantity of water having low chloride concentrations, by use of a well couple, depends on the upward movement of saltwater within the aquifer when the well is pumped. Upward movement of saltwater depends on the relative concentrations of chloride in the borehole and on the distribution of horizontal and vertical hydraulic conductivity of the aquifer.

For any well screened in an aquifer that contains both freshwater and saltwater, a family of curves can be constructed to represent all combinations of pumping rates and corresponding chloride loads when the scavenger well and the production well are being pumped simultaneously. The curves permit estimates of optimal withdrawals of freshwater based on the desired pumping rates and the levels of chloride concentration required for each well.
\end{abstract}

\section{INTRODUCTION}

\section{Background}

The presence of saltwater in aquifers throughout the coastal areas of Puerto Rico has caused many wells to be abandoned and threatens the further development of groundwater resources in these areas. Salty ground water can result from either seawater encroachment or as a mix of residual seawater and freshwater from aquifer recharge. Seawater encroachment occurs when large ground-water withdrawals lower the water table or potentiometric surface such that the hydraulic gradient is reversed between the ocean and inland pumping areas or when heavy pumpage causes upconing of underlying saltwater. Saltwater occupies most of the surficial sediments near the coast in Puerto Rico; freshwater in these areas occurs as a thin layer above the saltwater.

Where wells are completed within the thin freshwater layer and the well is pumped, the underlying saltwater usually advances toward the well. The movement of saltwater can sometimes be controlled by reducing the pumping rate. Ground-water withdrawals from a well open to both freshwater and saltwater zones, however, will necessarily cause saltwater to be drawn into the well bore, resulting in abandonment of the well if the concentration of dissolved solids is sufficiently high. Cementing the saltwater zone of wells has proved unsatisfactory because withdrawal from the remaining freshwater zone continues to produce upward movement of saltwater within the aquifer even though the well is no longer directly open to the saltwater zone.

\section{Purpose and Scope}

The U.S. Geological Survey in cooperation with the Water Resources Research Institute, University of Puerto Rico, Mayagüez Campus, conducted a study of scavenger/ production well systems and design alternatives during 1983 and 1984. This report describes the results of hydraulic analyses of a scavenger/production well system that can aid freshwater development from aquifers in coastal areas of Puerto Rico and elsewhere.

\section{Study Area: Location and Hydrologic Setting}

The investigation was conducted in an abandoned well at Barrio La Trocha, near Vega Baja in north-central Puerto Rico (fig. 1). The well is screened both in freshwater and saltwater parts of the relatively permeable Aymamón Limestone aquifer of Miocene age. The water-table aquifer in northern Puerto Rico occurs principally in the Aymamón Limestone (Giusti and Bennett, 1976).

The freshwater-saltwater system at La Trocha has evolved as a result of dilution of connate seawater by rainwater that percolates downward into the Aymamón Limestone aquifer. Eventually, at a given static sea level, saltwater is flushed from the aquifer and a freshwater-seawater interface is established downgradient toward the ocean. The flushing action in the aquifer where saltwater occurs is foreshortened, however, by the tendency of the freshwater to travel downgradient above the more dense freshwater-saltwater mixture. Consequently, a large amount of the freshwater is discharged to the ocean and is relatively ineffective in diluting and flushing out the deeper, saltier water. 
Water within the aquifer at $\mathrm{La}$ Trocha is referred to as "freshwater" or "saltwater" in this report depending on whether it is derived from the upper or lower part of the aquifer. The boundary between freshwater and saltwater is at a depth of about $130 \mathrm{ft}$, where water that has a specific conductance of about $2,000 \mu \mathrm{S} / \mathrm{cm}$ or about $500 \mathrm{mg} / \mathrm{L}$ chloride occurs. Use of these numbers is relative because of the gradational nature of salinity in the aquifer.

\section{Theory and Operation of Recovery Wells}

Scavenger/production well coupling is a technique that can be used to selectively recover some quantity of freshwater from a well that is screened in an aquifer that contains both freshwater and saltwater. The well couples can be installed either as two adjacent wells screened on either side of the freshwater-saltwater interface within the aquifer or as two wells placed within a single larger well that is screened in both freshwater and saltwater zones. In each case, the intake of the production well is placed in the freshwater zone, as far as possible above the saltwater zone. The intake of the

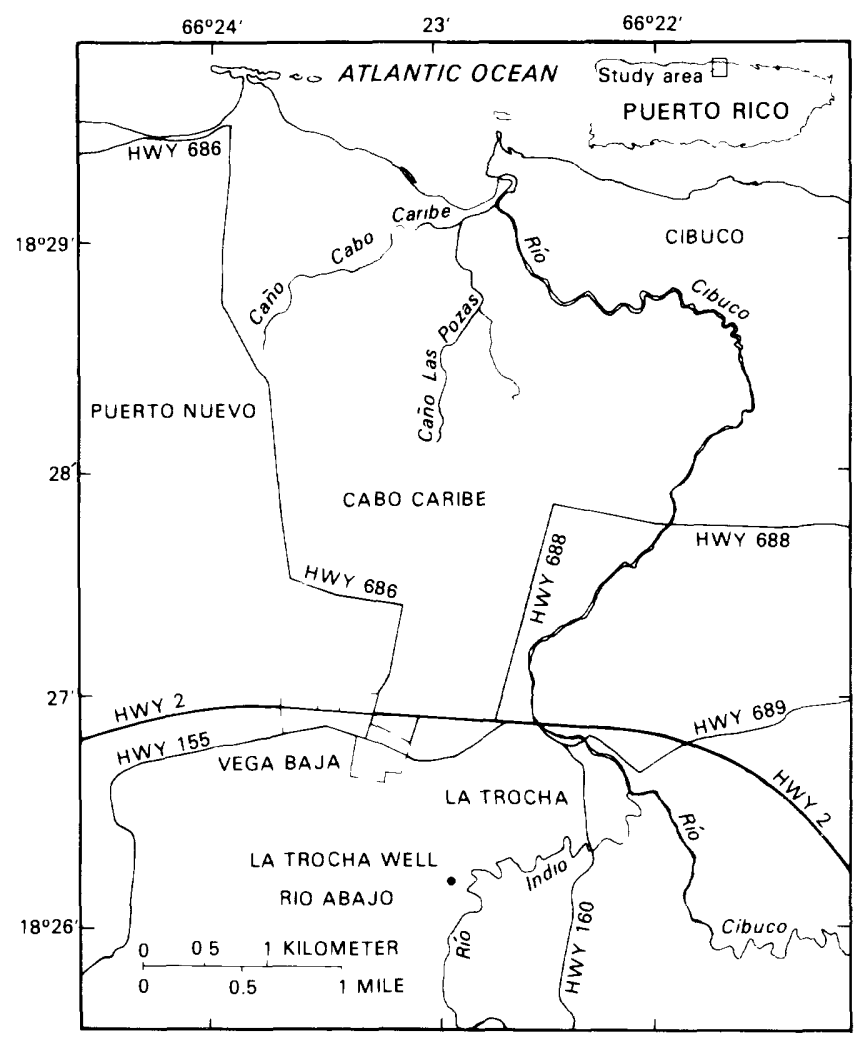

Figure 1. Principal geographic features of Vega Baja area, Puerto Rico, and location of La Trocha well. scavenger well is placed within the saltwater zone. Although scavenger/production well couples generally operate more efficiently when placed in the aquifer as separate wells, there is a need in Puerto Rico for developing a method to reclaim freshwater from wells that have been abandoned because they were inadvertently screened in both freshwater and saltwater zones of the aquifer.

The scavenger well and the production well each pump at a selected rate from appropriate depths within a larger well and are screened in the saltwater and freshwater zones, respectively; each extracts part of the water that enters the well bore. The respective quantities of saltwater and freshwater that enter the well bore depend on the vertical distribution of saltwater and freshwater and on the hydraulic conductivity of aquifer material open to the well screens. Theoretically, scavengerwell withdrawals of saltwater at a selected rate permit the simultaneous optimum withdrawal of water of acceptable quality for the water's intended use from the production well. The salty water that enters the borehole is extracted by the scavenger well before it can migrate toward the productionwell intake. The salty water withdrawn by the system is usually pumped to waste.

In the past, well couples have not been considered as a means of selectively extracting freshwater from coastal aquifers because of uncertainties associated with well-screen placement and the optimum conjunctive pumping rates required to produce a usable quantity of freshwater. In fact, where scavenger/production well couples have been used (outside of Puerto Rico), the most efficient operation of the couple has usually been achieved by trial and error in adjustment of well-screen placement and conjunctive pumping rates. However, by applying a relatively straightforward hydraulic analysis, described herein, the most efficient correspondence of pumping rates and intake locations of the scavenger and production wells can be made. This correspondence is achieved by measuring the vertical movement of saltwater within the well and within the aquifer as pumping stresses are applied and by describing the appropriate hydraulic controls such as differences in transverse hydraulic conductivity across the vertical section of aquifer material open to the well. In this way, the feasibility of using the scavenger/production well couple to produce freshwater from an aquifer that contains saltwater can be assessed, and engineering decisions concerning the development of freshwater can be made.

Scavenger/production well couples are not particularly cost-efficient because of the added expense of an additional well, pump, and electricity or fuel. In addition, where no suitable discharge site is available for the withdrawn saltwater, the system cannot be operated. Nevertheless, given an acceptable saltwater-disposal site and sufficient need for a freshwater supply, scavenger/production well couples may be a means of developing freshwater supplies in coastal aquifers. This technique could be especially useful where the the thin layer of freshwater, which overlies saltwater, cannot be developed by conventional methods.

2 A Well System to Recover Usable Water from a Freshwater-Saltwater Aquifer in Puerto Rico 


\section{Hydraulic Theory of Vertical Saltwater Movement}

The amount of saltwater a well yields from a saltwaterfreshwater zone depends on the pumping rate, the location of freshwater and saltwater in the aquifer, the location of the well screens in the aquifer, and the distribution of horizontal and vertical hydraulic conductivity within the aquifer (which determines the distribution of head that develops in the aquifer during pumping).

Wells that fully penetrate an aquifer that contains both freshwater and saltwater draw both freshwater and saltwater into the well bore when the wells are first pumped. Wells that partially penetrate the aquifer and are completed in the freshwater zone may cause saltwater to move upward (upconing) as the wells are pumped. Saltwater is less accessible to the borehole in these partially penetrating wells because more energy is required to "lift" the saltwater into the well bore than in instances where the wells actually penetrate the saltwater. The degree and behavior of vertical movement of saltwater, therefore, depend on the distribution of horizontal and vertical hydraulic conductivity and whether the well fully or partially penetrates the aquifer.

A well that fully penetrates a freshwater-saltwaterbearing aquifer that is isotropic with respect to horizontal hydraulic conductivity (transversely isotropic) will not produce a vertical flow component, regardless of variations in vertical hydraulic conductivity (fig. $2 A$ ). The well admits water at the same rate at every point along the well bore; both freshwater and saltwater enter the well, but upward movement of saltwater does not occur within the aquifer. However, if an aquifer is partially penetrated by a well completed only in the freshwater zone and is transversely isotropic or isotropic with respect to horizontal and vertical hydraulic conductivity, upward movement of saltwater will occur (fig. 2B). Flow lines to the well develop from all directions, including a vertical flow component from beneath the well. If the aquifer has considerably greater horizontal hydraulic conductivity as compared to vertical, there will be proportionately more horizontal flow than vertical, and upward movement will be less (fig. 2C). However, where vertical fractures or conduits occur, an aquifer will have a large vertical hydraulic conductivity as compared to horizontal, and upward movement of saltwater will proceed more rapidly (fig. $2 D$ ).

Flow lines and equipotential lines of pressure head within aquifers are more complicated in layered systems that are characterized by transverse isotropy but that have different values of horizontal hydraulic conductivity in each layer (fig. 3). When either a partially or fully penetrating well is pumped, flow lines converge in the more hydraulically conductive layers. Within the aquifer, a vertical flow component develops from layers of low hydraulic conductivity toward those of high conductivity (fig. 3). In general, movement of saltwater will follow the flow lines that develop according to the ratios of horizontal to vertical hydraulic conductivity within the aquifer.
Movement of saltwater in a fully penetrating well behaves like that in a partially penetrating well when differences in horizontal hydraulic conductivity in the screened aquifer become large. In the extreme case when part of the
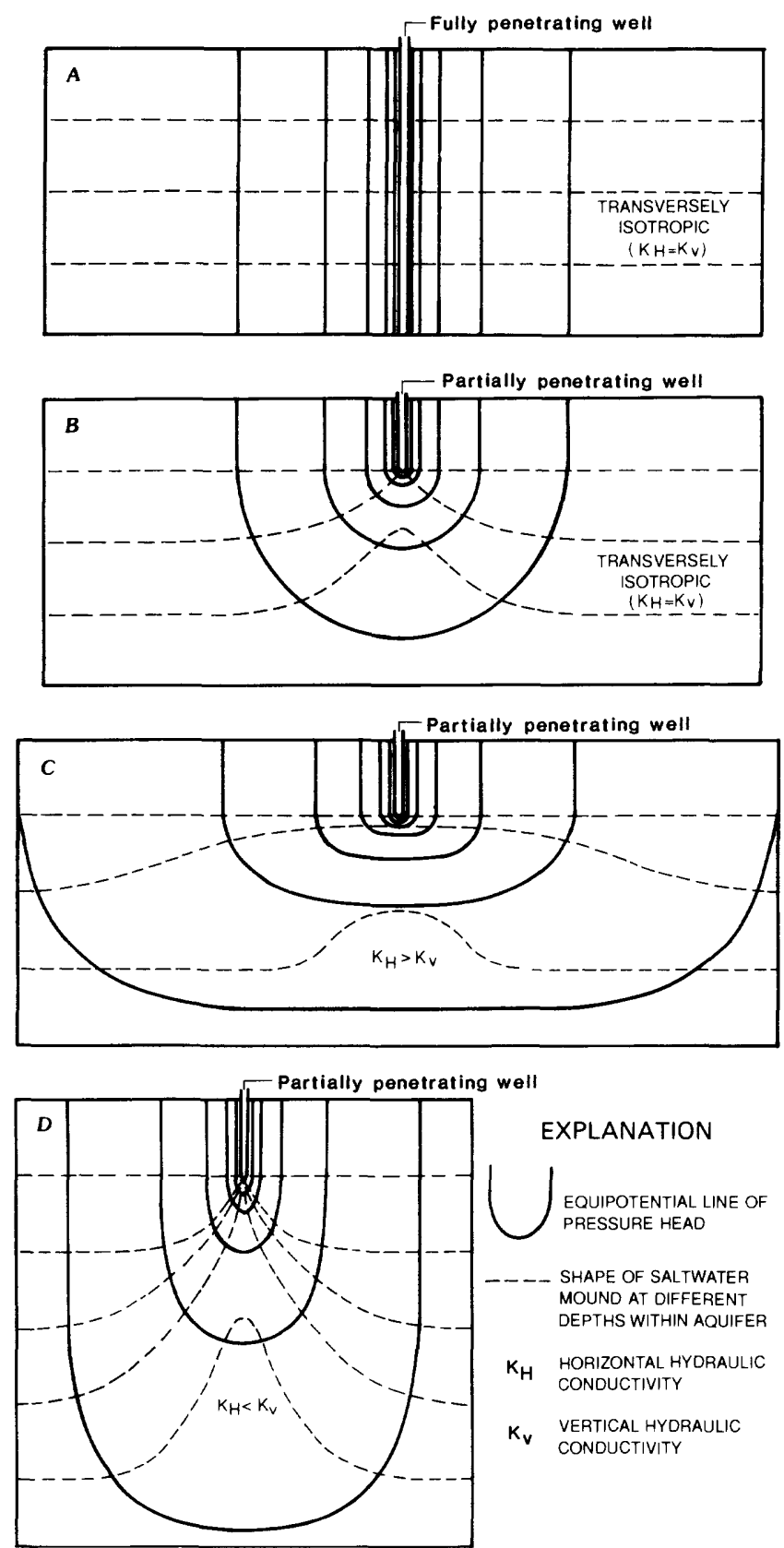

Figure 2. Schematic diagrams showing equipotential lines and upward movement of saltwater. $A$, Fully penetrating well, aquifer transversely isotropic. $B$, Partially penetrating well, aquifer isotropic with respect to horizontal and vertical hydraulic conductivity. $C$, Partially penetrating well, horizontal hydraulic conductivity greater than vertical. $D$, Partially penetrating well, vertical hydraulic conductivity greater than horizontal. 
fully penetrated aquifer has a horizontal hydraulic conductivity of nearly zero (fig. $3 B$ ), the movement of saltwater responds to pumping stresses as if the aquifer is partially penetrated (fig. $3 C$ ). The aquifer system responds to pumping stresses differently in terms of head distribution, but the effects, in terms of the quantity of saltwater produced by the well (the mix of water achieved), are similar.

As a well is pumped at a constant rate, the upconing of the saltwater stabilizes because of differences in the density and dynamic viscosity of the freshwater and saltwater within the aquifer. According to Darcy's law, the amount of water that enters a borehole along its length depends on the hydraulic gradient, the permeability of aquifer materials, and the density and dynamic viscosity of aquifer fluids at every point. As pumping starts, the permeability of the waterbearing materials and the hydraulic gradient exert the greatest control on the proportion of freshwater and saltwater that flows into the well bore; as differences in hydraulic gradient along the well bore become smaller with time, the fluid properties of density and dynamic viscosity become more

FULLY PENETRATING WELL

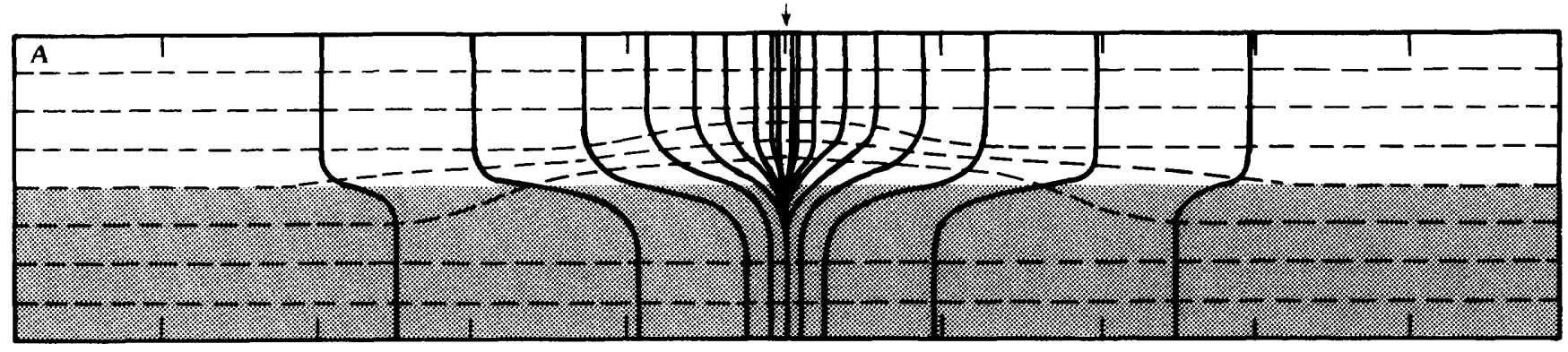

FULLY PENETRATING WELL

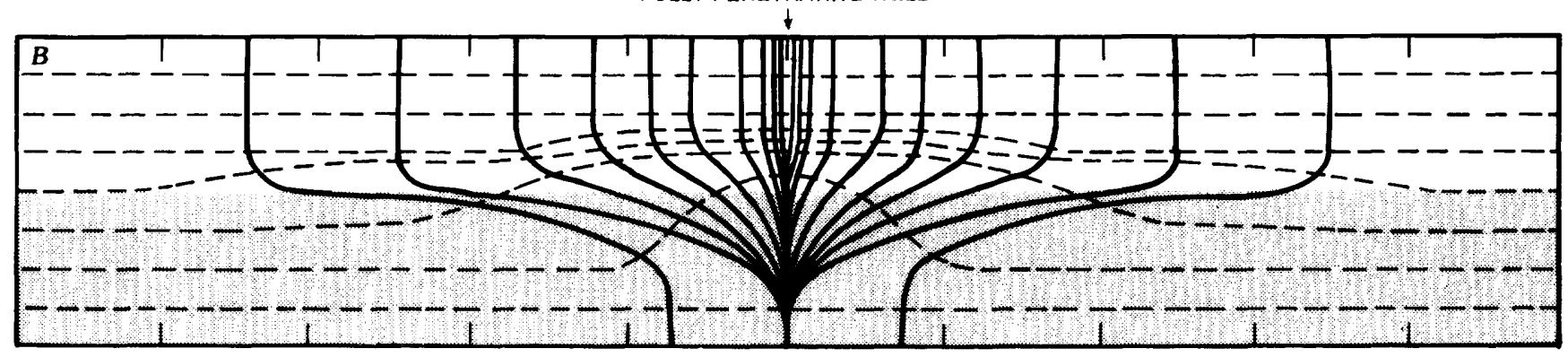

PARTIALLY PENETRATING WELL

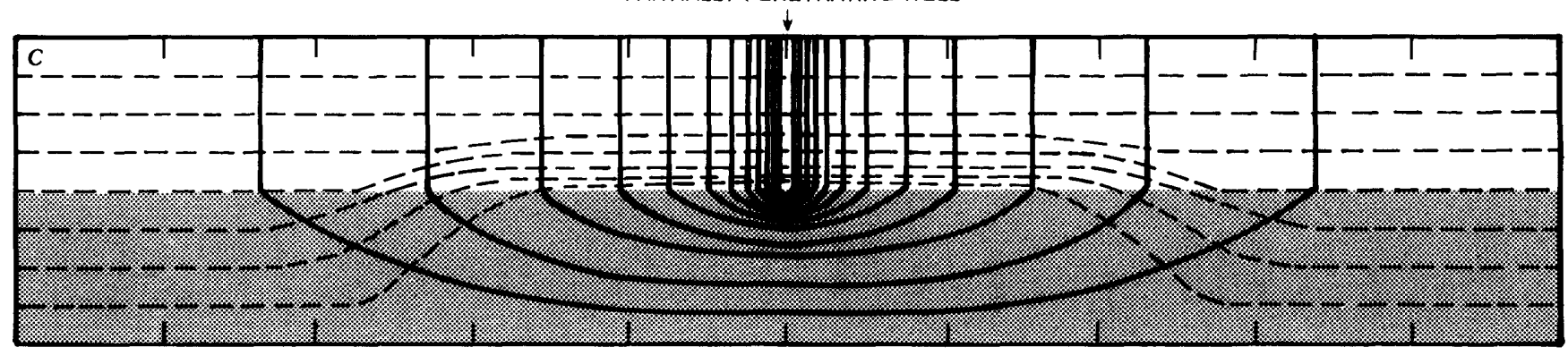

EXPLANATION
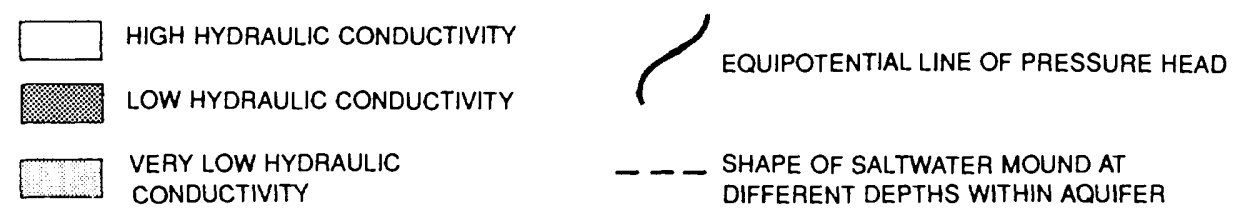

Figure 3. Schematic diagrams showing equipotential lines and saltwater response to ground-water withdrawals from fully penetrating and partially penetrating wells in anisotropic aquifers $A, B$, and $C$ having vertical differences in horizontal hydraulic conductivity. 
important. Ultimately, a balance between the hydraulic gradient and fluid properties is achieved; the height and shape of the upward-moving saltwater cone reach equilibrium, and the chloride concentration of the composite water withdrawn from the well, which is pumped at a constant rate, is stabilized.

In an aquifer partially penetrated by a well that is screened above the freshwater-saltwater interface, saltwater will migrate upward until the upward hydraulic gradient becomes negligible. If this occurs before the interface reaches the well screen, the well will not produce saltwater.

The redistribution of water in a freshwater-saltwaterbearing aquifer in response to pumping from a fully penetrating well is not considered to be saltwater upconing in the classic sense but is due to the vertical distribution of horizontal hydraulic conductivity within the aquifer. Vertical hydraulic conductivity exerts the greatest control on vertical movement of saltwater nearest the pumping well (where heads across the stressed aquifer are most disparate). Intuitively, if freshwater parts of the aquifer have greater horizontal hydraulic conductivity than underlying saltwater parts (fig. 3), saltwater will migrate upward within the aquifer (if vertical hydraulic conductivity is sufficiently large) in response to vertical differences in the head when the well is pumped. Flow lines converge in the freshwater part of the aquifer where the greatest hydraulic conductivities occur. This convergence provides an upward hydraulic gradient and influences the shape of the saltwater cone, which is mound shaped in the aquifer (fig. 3). The saltwater mound broadens as equilibrium conditions are achieved. If the saltwater parts of the aquifer have greater hydraulic conductivity than the freshwater parts, a downward hydraulic gradient will develop when the well is pumped, and freshwater will migrate downward in the aquifer and create a freshwater basin within the saltwater zone.

The proportion of water that enters the well at every point along its length open to the aquifer remains the same at each withdrawal rate, even though the aquifer exhibits differences in transverse isotropy along the vertical section. The proportions remain the same as the saltwater moves upward (or freshwater downward) within the aquifer in response to vertical flow components if the efficiency of the well does not vary with pumping rate (except for very small influences from fluid density and dynamic viscosity). In effect, the saltwater section of the aquifer becomes thicker and the freshwater part thinner, or vice versa, in the vicinity of the well as the pumping rate is increased, but the proportion of water that enters the borehole along its length remains the same.

\section{SCAVENGER/PRODUCTION WELL SYSTEMS}

\section{Description of Demonstration Well}

An abandoned water-supply well drilled in 1969 by the Puerto Rico Aqueduct and Sewer Authority at Barrio La Trocha near Vega Baja was used during the investigation.
The well was initially drilled to a depth of $192 \mathrm{ft}$ and cased to $100 \mathrm{ft}$ with 16-in. black iron pipe. Perforated pipe 16 in. in diameter, which extends from 100 to $192 \mathrm{ft}$, is open to the Aymamón Limestone. The well had a relatively high specific capacity of $95(\mathrm{gal} / \mathrm{min}) / \mathrm{ft}$ (gallons per minute per foot of drawdown) at withdrawal rates in excess of 200 $\mathrm{gal} / \mathrm{min}$. A limited amount of freshwater having a specific conductance of 760 to $1,100 \mu \mathrm{S} / \mathrm{cm}$ at $25^{\circ} \mathrm{C}$ (microsiemens per centimeter, at $25^{\circ} \mathrm{Celsius)}$ or an equivalent chloride concentration of about 100 to $200 \mathrm{mg} / \mathrm{L}$ (milligrams per liter) occurred at a depth of about $100 \mathrm{ft}$. However, the need for larger quantities of water at the site prompted the deepening of the well. The specific conductance of water in the deepened well under static conditions increases with depth from $760 \mu \mathrm{S} / \mathrm{cm}(100 \mathrm{mg} / \mathrm{L}$ chloride) at $100 \mathrm{ft}$ to $5,500 \mu \mathrm{S} / \mathrm{cm}$ $(2,020 \mathrm{mg} / \mathrm{L}$ chloride $)$ at $190 \mathrm{ft}$. The well was abandoned because, even at low pumping rates, the water produced was of unacceptable quality for human consumption (minimum of $1,550 \mu \mathrm{S} / \mathrm{cm}$ specific conductance or $321 \mathrm{mg} / \mathrm{L}$ chloride).

The vertical distribution of specific conductance in the well at La Trocha, which was idle for 14 years, reflects the mixing and dispersion mechanism that has occurred in the Aymamón Limestone aquifer-namely, an increasing salinity gradient with depth.

A well (USGS-1) was drilled $8.5 \mathrm{ft}$ away from the La Trocha well and was screened entirely within the freshwater part of the aquifer between 99 and $109 \mathrm{ft}$ below land surface. Both the La Trocha well and well USGS-1 were used to observe the upward movement of saltwater within the aquifer when well USGS-1 was pumped. Later, the La Trocha well itself was pumped to monitor the degree and behavior of vertical movement of saltwater within the aquifer.

\section{Vertical Movement of Saltwater at Well Site}

Well USGS-1 was initially pumped at $53 \mathrm{gal} / \mathrm{min}$ and yielded water having a specific conductance of $900 \mu \mathrm{S} / \mathrm{cm}$. Within 300 minutes, the specific conductance increased to and stabilized at $1,120 \mu \mathrm{S} / \mathrm{cm}$. Flow-velocity surveys (by use of brine injection and flowmeters) and depth profiles of specific conductance of water in the La Trocha well were obtained at different times (fig. 4). Upward flow of zero that was measured in the La Trocha well indicated that water probably was not transferred through the well bore from saltwater to freshwater parts of the aquifer. The profiles of specific conductance obtained in the La Trocha well during the pumping of well USGS- 1 indicated that water of relatively high specific conductance (greater than $2,000 \mu \mathrm{S} / \mathrm{cm}$ from a depth of $130 \mathrm{ft}$ ) was moving upward (downgradient in terms of hydraulic head) toward the most hydraulically conductive parts of the aquifer, located at depths of about 100 to $105 \mathrm{ft}$. Saltwater was monitored as it moved upward within the aquifer, gradually replacing the freshwater that originally occupied the aquifer at depths from 100 to $130 \mathrm{ft}$. 
After the USGS-1 well was pumped for 380 minutes, specific conductance and the upward movement of saltwater (fig. 4) had stabilized in the La Trocha well.

The degree and behavior of vertical movement of saltwater within the aquifer also were monitored to measure the amount of freshwater replaced by upward-moving saltwater as the La Trocha well itself was pumped at different rates. A variable-discharge submersible pump was placed within the well casing at a depth of 60 feet, and water was withdrawn at rates of $18,24,30,36$, and $54 \mathrm{gal} / \mathrm{min}$. Negligible (less than $1 \mathrm{ft}$ ) water-level drawdown was measured in the well when pumped at these low rates of discharge because of the high transmissivity $(24,000$ square feet per day, $\mathrm{ft}^{2} / \mathrm{d}$ ) estimated for the aquifer.

Water samples were collected for each individual pumping rate and were analyzed for specific conductance and chloride concentration. The water withdrawn represents a composite of all water entering the well across the screened extent of the aquifer. Specific conductance of withdrawn water samples was plotted against the time of water-sample collection (fig. 5). Had salinity at various depths within the aquifer remained constant during pumping, the specific conductance of the withdrawn water samples would have remained constant during each of the five pumping conditions, and no vertical movement of saltwater within the

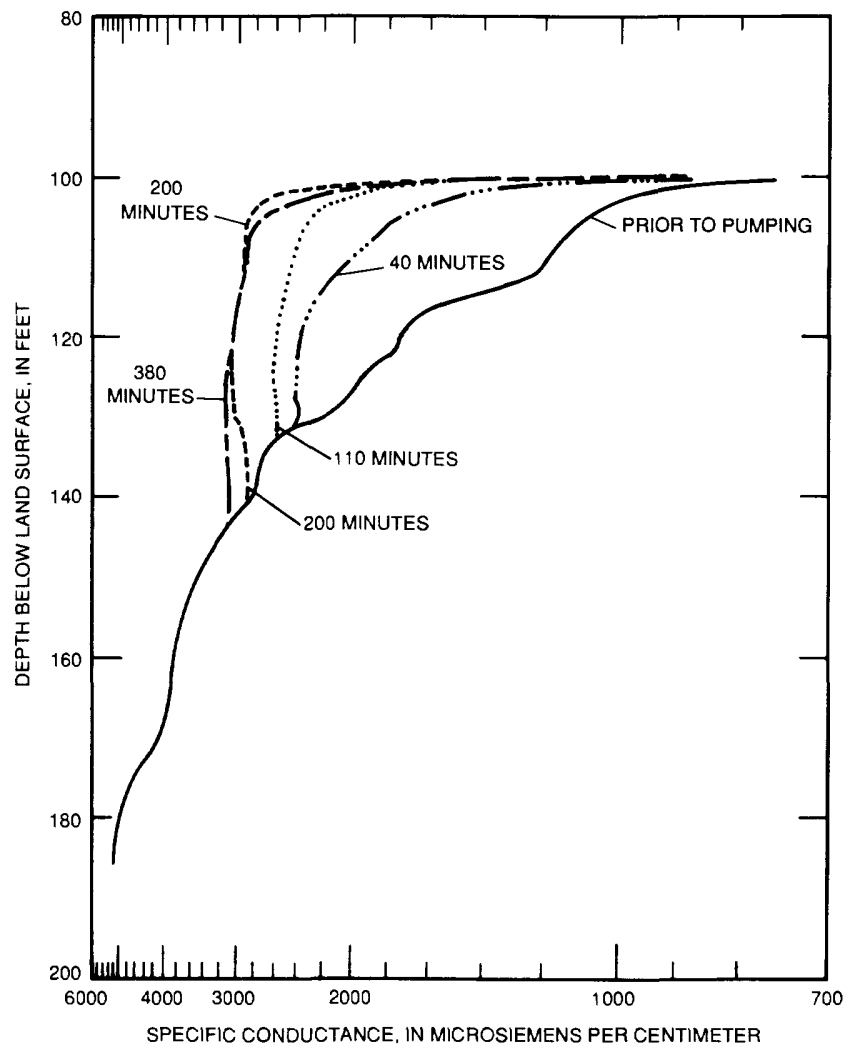

Figure 4. Depth/specific-conductance profiles at various times in La Trocha well as nearby USGS-1 well is pumped at 53 gallons per minute. aquifer would have occurred. However, the fact that specific conductance increased during each of the five different withdrawal conditions does indicate that saltwater was moving upward within the aquifer as pumping progressed. When the specific conductance of the withdrawn water had stabilized for each of the five pumping rates, depth profiles of specific conductance and flowmeter surveys were made. Saltwater had migrated upward within the aquifer in response to upward vertical flow components produced by pumping from the freshwater section of the aquifer, which has a greater horizontal hydraulic conductivity than the saltwater section. Higher pumping rates were associated with greater upward migration of saltwater and attendant higher stabilized values of specific conductance than those at lower pumping rates.

Profiles of specific conductance and flowmeter surveys (examples in fig. 6) indicate that although the well was screened from 100 to $192 \mathrm{ft}$, it only admitted measurable quantities of water from depths of 100 to $145 \mathrm{ft}$. The amount of water entering the well bore reflected the strong vertical inhomogeneity of horizontal hydraulic conductivity in the aquifer. In fact, 40 percent of all the water withdrawn from the La Trocha well entered the well bore through the upper $2 \mathrm{ft}$ of aquifer open to the well. Water at a depth of 130 to $145 \mathrm{ft}$ has an average specific conductance of $3,000 \mu \mathrm{S} / \mathrm{cm}$ or $880 \mathrm{mg} / \mathrm{L}$ chloride concentration. As this relatively salty water moved upward in the well, it mixed with less-salty water from shallow zones and produced a different specificconductance profile for each pumping rate (see examples for 18- and 54-gal/min pumping rates in fig. 6). After pumping ceased, the vertical distribution of specific conductance of water in the well returned to its original prepumping profile within hours.

Data that represented stabilized chloride concentrations in water withdrawn at the various pumping rates from the La Trocha well were used to develop the relation between the pumping rate (in gallons per minute) and the specific conductance (or chloride concentration) of water withdrawn (fig. 7). The level of stabilized chloride concentration in the water depended on the ultimate height of the saltwater mound that encroached into the freshwater part of the aquifer. The chloride concentration of water increased as the pumping rate increased because a progressively greater part of the screened interval of the well admitted saltwater as the mound of saltwater rose. The upward movement of saltwater from depths of 130 to $145 \mathrm{ft}$, however, was slowed by freshwater that entered the well from more shallow zones at a progressively greater velocity (as pumping rate increased) but through a progressively thinner freshwater part of the screened interval. The specific conductance and chloride concentration in water withdrawn (fig. 7) increased from a lower limit, which represented the freshest mix of freshwater and saltwater available to the well, to an upper limit that represented the saltiest mix of freshwater and saltwater theoretically attainable by saltwater upconing through the entire aquifer. The 
curve representing increased specific conductance and chloride concentration departed from the freshest-mix limit and approached the saltiest-mix limit asymptotically.

\section{Determination of Optimal Freshwater Discharge from Production Well}

Optimal freshwater discharges from a scavenger/ production well couple can be determined most conveniently by using chloride load, which is defined as chloride concentration multiplied by flow rate. Chloride load, expressed in units of grams per minute, does not involve dual ratios ( $\mathrm{gal} / \mathrm{min}$ and $\mathrm{mg} / \mathrm{L}$ ) and is easier to manipulate mathematically. The relation between chloride concentration and various pumping rates (fig. 7) can be represented as a chloride-load curve (fig. 8). In this form, the chloride-load curve reveals significant hydraulic considerations not apparent in the chloride-concentration curve shown in figure 7.

When chloride load is plotted as a function of pumping rate, the relation is linear, except at very low withdrawal rates. The chloride-load curve (line B) shown in figure 8 represents the combined load of freshwater and saltwater recorded from the well. If the chloride concentration of withdrawn water remains constant and equal at all withdrawal rates, a perfect alignment of points through the origin of abscissa and ordinate is defined, and upward movement of saltwater has not occurred. However, line B in figure 8 shows that the chloride load increases faster than can be attributed to increasing pumping rate at a constant chloride concentration. This increasing chloride load indicates that a larger part of the screen interval is becoming open to saltwater.

The chloride-load curve in figure 8 is linear, except near the zero pumping rate, because water flows radially to the well during pumping, and vertical differences in horizontal hydraulic conductivity remain constant. The above conditions in an aquifer, however, permit upward (or downward) movement of saltwater, which causes increases (or decreases) in chloride concentration in water samples withdrawn from the well. If aquifer materials were transversely anisotropic or if the well were not properly developed, the relation between chloride load and pumping rate would not be linear, due to nonradial flow to the well or to a changing proportion of water entering the well at points along the screen at different pumping rates.

At very low pumping rates, the effects of differences in transverse isotropy along the vertical section do not cause substantial vertical flow components within the aquifer, and water moves radially through the aquifer to the well. As pumping rate is increased, water in the aquifer is influenced by differences in transverse isotropy along the vertical section; vertical flow components become prominent, and upward movement of saltwater occurs.

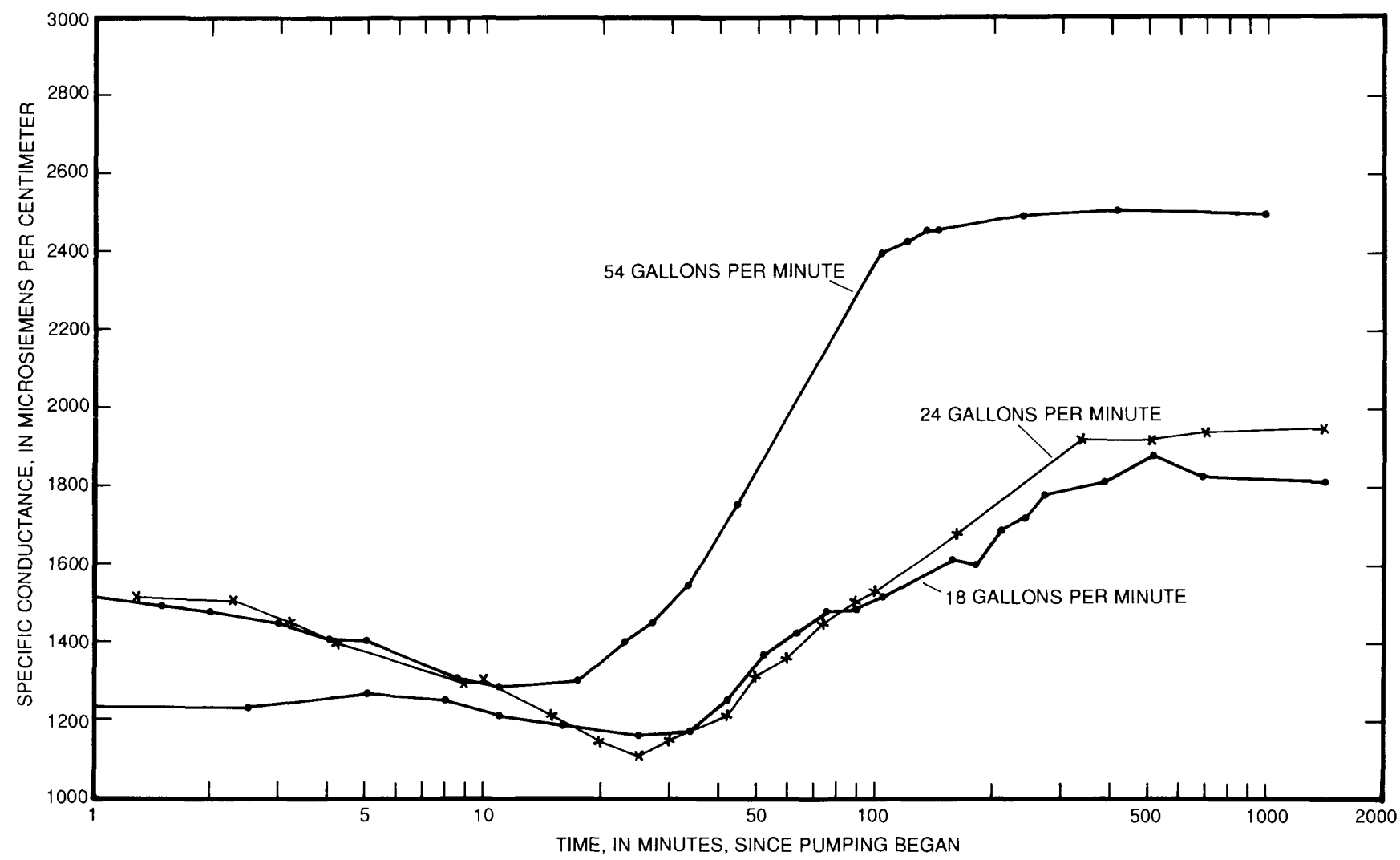

Figure 5. Examples of time/specific-conductance profiles of water withdrawn from La Trocha well at various pumping rates. 
Line $\mathrm{A}$ in figure 8, parallel to most of the chlorideload curve (line B), represents a theoretical constant chloride concentration of the upward-advancing saltwater mound, 880 $\mathrm{mg} / \mathrm{L}$. However, the saltwater mound is unable to progress completely through the freshwater part of the aquifer, entirely replacing it, because freshwater from shallow zones continuously enters the borehole, albeit through an everdecreasing length of the well-screen interval. The offset of lines $A$ and $B$ in figure 8 indirectly represents a measure of vertical differences in horizontal hydraulic conductivity that occurs in the screened part of the aquifer. The greater the separation between the lines, the greater the disparity in values of horizontal hydraulic conductivity. If the chlorideload curve were above and parallel to the $880-\mathrm{mg} / \mathrm{L}$ chloride line, the saltwater part of the aquifer would have a higher horizontal hydraulic conductivity than the overlying freshwater part. The $321-\mathrm{mg} / \mathrm{L}$ chloride line (line $\mathrm{C}$ ) that is tangent to the chloride-load curve (line B) represents the freshest mix of water available to the well (fig. 7). Water having a chloride concentration of $321 \mathrm{mg} / \mathrm{L}$ would have been obtained for all pumping rates if vertical isotropy prevailed in the aquifer.

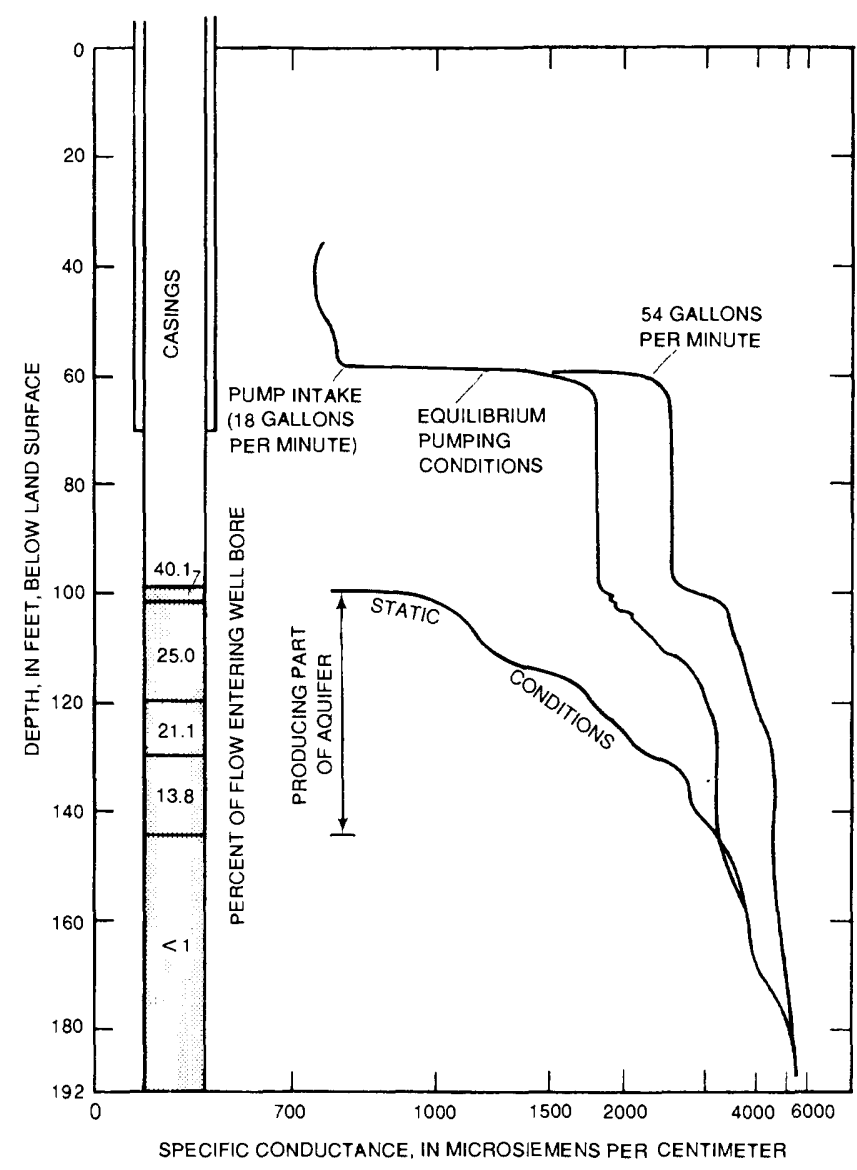

Figure 6. Static and pumping specific-conductance profiles and flowmeter results, La Trocha well.
The linear correlation between chloride load and pumping rate, as observed in figure 8 , can be applied at other similar sites where the salinity of the saltwater mound and its propensity for moving upward at various pumping rates are unknown. By measuring a sufficient number of chloride loads at different pumping rates for any well screened or open to both freshwater and saltwater parts of a vertically anisotropic but transversely isotropic aquifer, it is possible to establish a linear relation. From this relation, the maximum salinity of the upward-moving saltwater and the freshest mix of freshwater and saltwater available to the wellcouple system can be determined graphically. The relation between chloride concentration and the withdrawal rate, and the height of upward movement of the saltwater mound, can also be estimated for higher pumping rates. A depth profile of specific conductance of the water in a well, both before and during pumping, yields additional information about the freshest and saltiest water available to the well.

Wells that partially penetrate the aquifer and that are screened only in the freshwater zones also follow the hydraulic theory, even if the upward movement of saltwater response to pumping stresses is attenuated by the increased energy required to "lift" the saltwater to the screens. In this case, the chloride-load curve similar to that shown in figure 8 will follow the line representing the freshest mix of freshwater and saltwater attainable by the well (fig. 7) until a

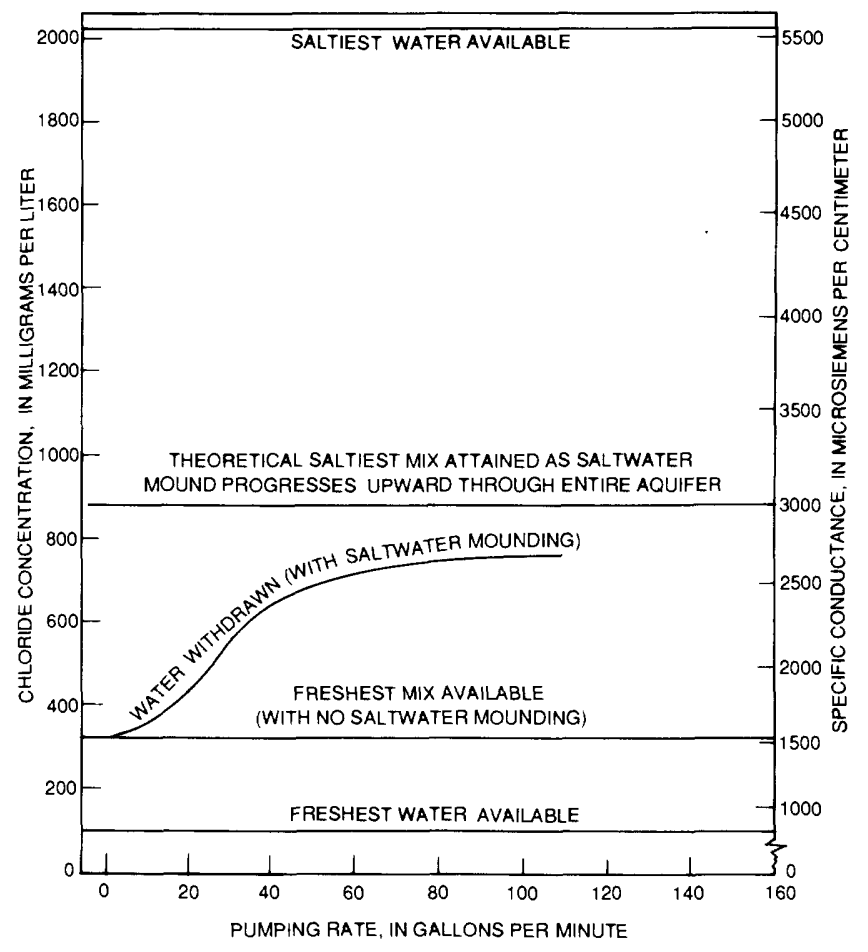

Figure 7. Chloride concentration and specific conductance of water withdrawn from La Trocha well at various pumping rates. 
pumping rate that is capable of "lifting" the saltwater to the screens is reached. As pumping rates are further increased, the chloride-load curve shifts upward, eventually becoming parallel to the line that represents the saltiest mix of water attainable by the well.

\section{Field Testing the Scavenger/Production Well System}

The behavior of the upward-moving saltwater at the La Trocha test site indicates that freshwater cannot be withdrawn from the well without some means of controlling saltwater intrusion. To field test the scavenger/production well couple at the La Trocha well, a small submersible pump was placed in the saltwater zone at a depth of $130 \mathrm{ft}$ to intercept or, at least, to retard the upward movement of saltwater in the well. That pump served as a scavenger well. The same variable-discharge submersible pump that was placed at a depth of $60 \mathrm{ft}$ and used earlier to develop the curves relating chloride concentration and chloride load to the pumping rates (figs. 7 and 8 , respectively) served as the production well. The two pumps were operated simulta-

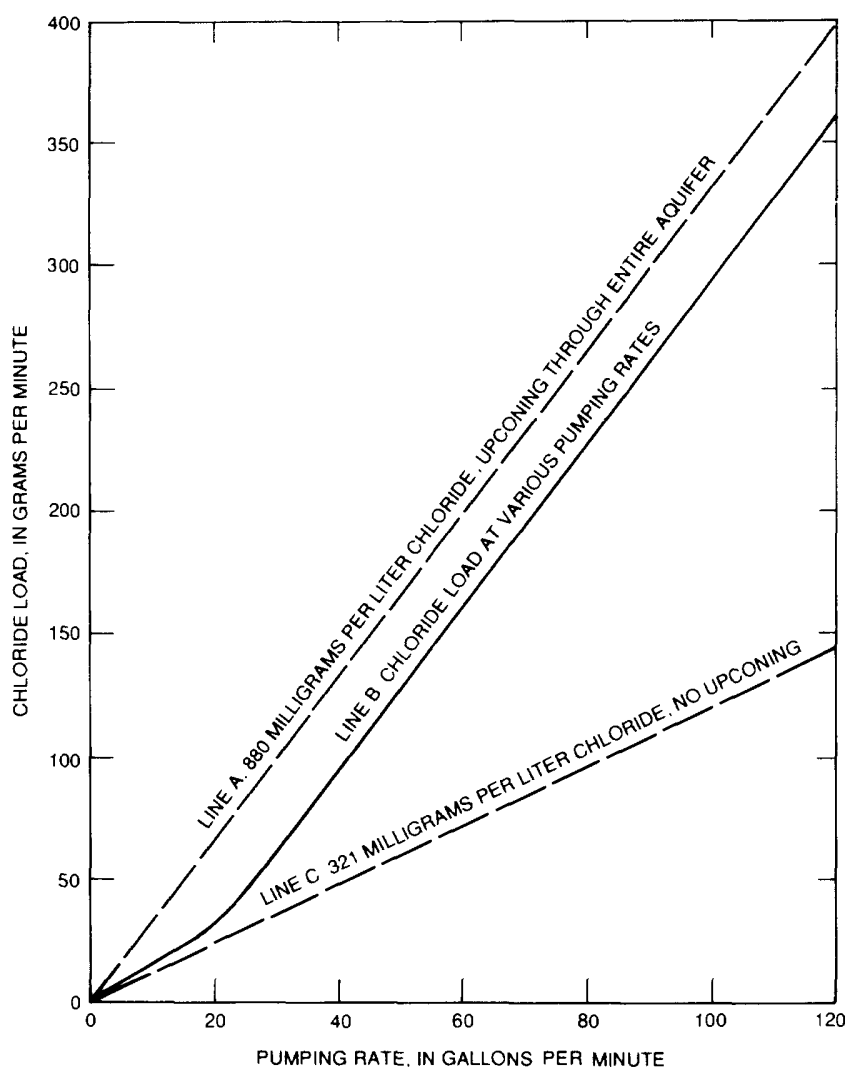

Figure 8. Chloride load of water withdrawn at various pumping rates from La Trocha well, and corresponding asymptotes that represent freshest and saltiest mixes of water attainable. neously; the scavenger well was pumped at a constant rate of $18 \mathrm{gal} / \mathrm{min}$ and the variable-discharge production well was pumped at rates of $18,24,30,36$, and $54 \mathrm{gal} / \mathrm{min}$.

After equilibrium chloride concentrations were attained during pumping of each well (see examples of time-specific conductance profiles in fig. 9), the flow rates and the corresponding chloride loads were combined for the scavenger well and production well at various pumping-rate combinations. A plot of these combined data indicate that they coincide with the linear chloride-load curve (line B) shown in figure 8 , which was earlier defined by data from the $\mathrm{La}$ Trocha well as it was pumped by the single pump placed at a depth of 60 feet. Apparently, the total chloride load pumped from the La Trocha well increases linearly, according to the total water withdrawn from the well-couple system, regardless of whether the chloride load and pumping rate represent withdrawals from one well or two.

The pump-intake locations of both the production and scavenger wells can affect the amount of water that enters the well at various points along the screen interval, particularly as pumping rates increase and in areas where aquifer transmissivities and well diameters are less. However, the low withdrawal rates and the large screen diameter of the La Trocha well cause a uniform head reduction throughout the well during pumping; water enters the well at a rate dependent on the hydraulic conductivity of only the part of the aquifer open to the well screen.

As part of field testing the well couple, many pumping combinations were performed at various scavenger- and production-well pump-intake depths at the La Trocha well. After equilibrium values of specific conductance of water withdrawn from both the scavenger and production wells were achieved, the sums of chloride loads and pumping rates for each pumping combination were calculated and plotted on the same grid as in figure 8 . The plotted data coincided with the chloride-load curve of figure 8 . Therefore, the total chloride load produced from the La Trocha well is the same as the sum of chloride loads produced by any combination of pumping rates when the scavenger and production wells are pumping simultaneously. At very high pumping rates, head losses caused by water that enters the production and scavenger wells under turbulent flow conditions might cause total chloride loads to deviate from the chloride-load curve shown in figure 8 .

The chloride-concentration and chloride-load data for the production well (pumped at variable discharge) and scavenger well (pumped at constant $18 \mathrm{gal} / \mathrm{min}$ ) are plotted in figures 10 and 11 , respectively. The curves shown in the figures demonstrate the utility of the well couple for producing freshwater from the aquifer. Although water that had a chloride concentration of less than $321 \mathrm{mg} / \mathrm{L}$ could not have been obtained from a single pump at the La Trocha well (fig. 7), the production well was capable of producing about $25 \mathrm{gal} / \mathrm{min}$ of water that had a chloride concentration of 250 $\mathrm{mg} / \mathrm{L}$, while the scavenger well pumped $18 \mathrm{gal} / \mathrm{min}$ of water 
that had as much as $1,230 \mathrm{mg} / \mathrm{L}$ chloride (dashed lines in fig. 10).

The linear relation and additive nature of the combined chloride loads and pumping rates for the scavenger/ production well couple described above can be used for development of other pumping-rate combinations, assuming that the linear relation of total chloride load and pumping rate shown in figure 8 continues to apply. After the total pumping rate and total chloride load of a well are established, the allotment of loads and pumping rates to various scavenger/production well-pumping combinations can proceed.

Assuming that the maximum chloride concentration of water attained by the scavenger well $(1,420 \mathrm{mg} / \mathrm{L})$ when pumping at $18 \mathrm{gal} / \mathrm{min}$ (fig. 10) will be the same at higher scavenger-well pumping rates (the maximum concentration of upward-moving saltwater available), the maximum chloride concentration will be approached asymptotically at larger scavenger-well withdrawal rates (arbitrarily selected at 36,54 , and $72 \mathrm{gal} / \mathrm{min}$ in fig. 12 ; curves $\mathrm{g}, \mathrm{h}$, i, respec-

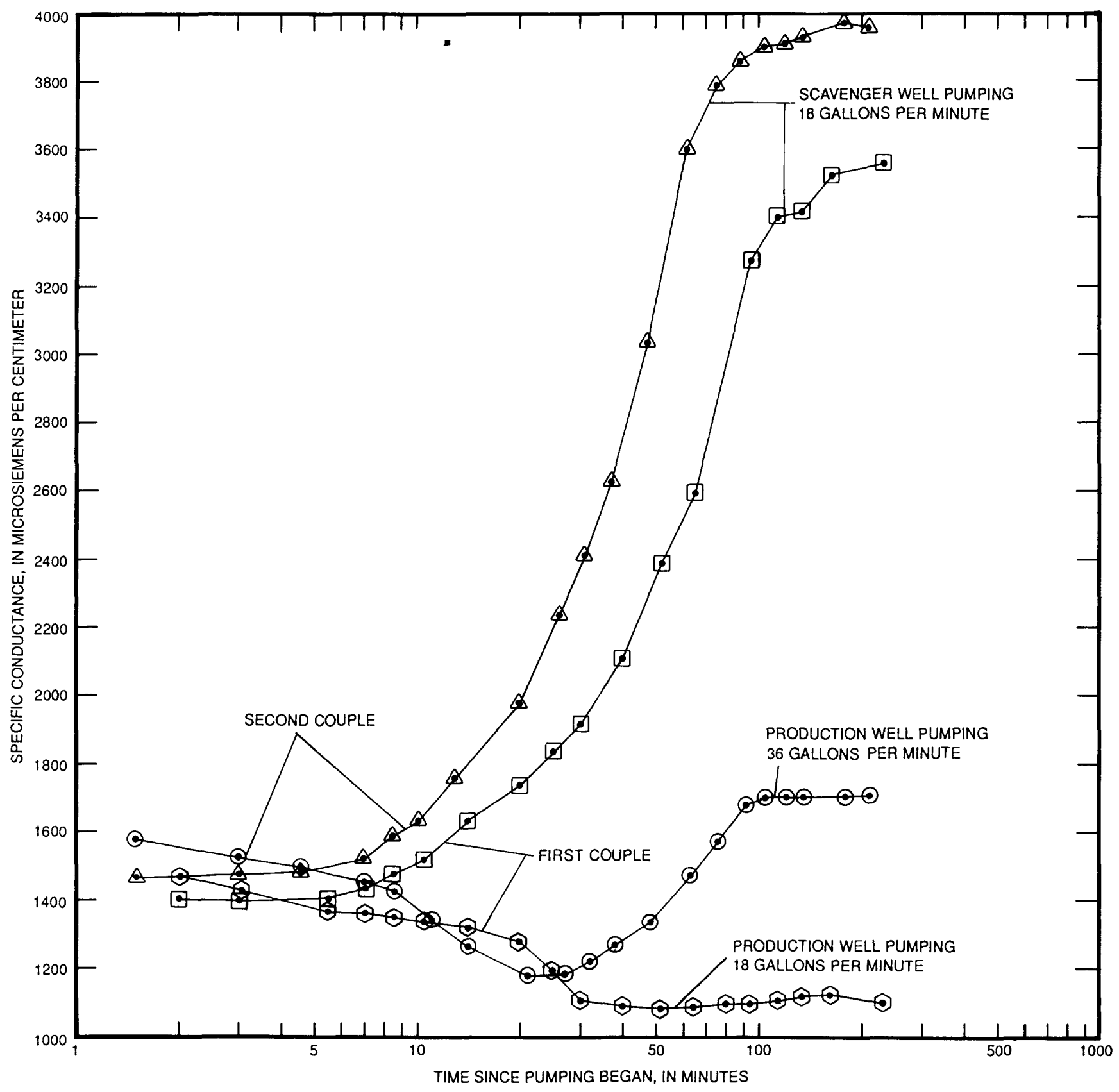

Figure 9. Examples of time/specific-conductance profiles for two scavenger/production well couples at different pumping rates. 
tively). Accordingly, chloride load of the production-well withdrawals increases with increasing pumping rate and approaches linearity at high rates of withdrawal (curves c, $\mathrm{d}$, e in fig. 12). The positions of the asymptotes approached by the respective curves are parallel, and each is determined by the quantity of saltwater pumped by the scavenger well. The chloride-load curves for the production well are automatically generated if it can be assumed that the additive phenomenon observed in figure 11 persists at higher pumping rates-namely, the chloride load of the production well (b) plus that of its scavenger well (c) is equal to the total chloride load of the wells. This amount equals the chloride load produced solely by the production well when the scavenger well is not pumped (a) and is represented by line B of fig. 8 .

An example of the relation between the pumping rates of the production and scavenger wells, in terms of the chloride loads produced by each well, is presented by dashed lines in figure 12. Total chloride load produced by the production and scavenger wells pumping together (at a combined pumpage of $80 \mathrm{gal} / \mathrm{min}$ ) is $229 \mathrm{grams}$ per minute, corresponding to a chloride concentration of $756 \mathrm{mg} / \mathrm{L}$. When a production well pumping $44 \mathrm{gal} / \mathrm{min}$ is pumped simultaneously with a scavenger well pumping $36 \mathrm{gal} / \mathrm{min}$ (line c), the chloride load is 56 grams per minute in the production well and 173 grams per minute in the scavenger well (line g), corresponding to chloride concentrations of 336

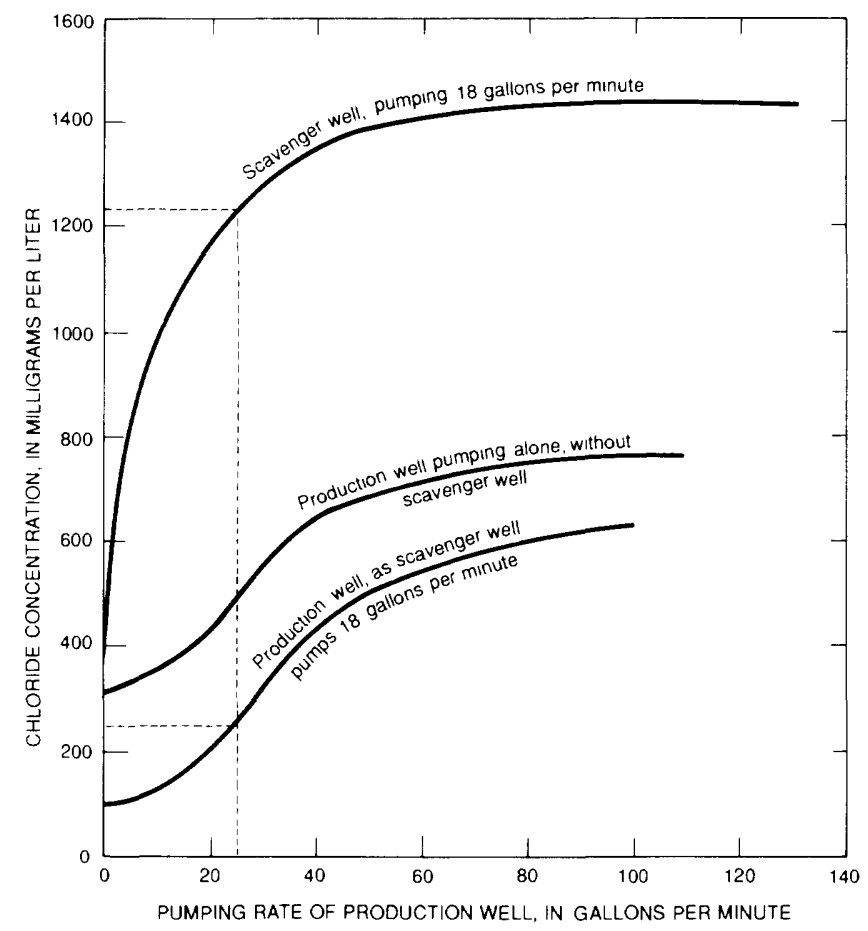

Figure 10. Chloride concentration of water withdrawn from La Trocha production well pumping at various rates while scavenger well pumps simultaneously at 0 or 18 gallons per minute. Dashed lines discussed in text. $\mathrm{mg} / \mathrm{L}$ and $1,270 \mathrm{mg} / \mathrm{L}$, respectively. Pumping $44 \mathrm{gal} / \mathrm{min}$ from the production well without using the scavenger well would have produced water having a chloride concentration of $670 \mathrm{mg} / \mathrm{L}$ (fig. 10).

The values of chloride load in figure 12 are converted to chloride concentration in figure 13. The dashed lines in figure 13 show that as much as $60 \mathrm{gal} / \mathrm{min}$ of water having $250 \mathrm{mg} / \mathrm{L}$ chloride can be withdrawn by the production well (i) if the scavenger well (d) simultaneously withdraws $72 \mathrm{gal} / \mathrm{min}$; approximately $40 \mathrm{gal} / \mathrm{min}$ of water having 250 $\mathrm{mg} / \mathrm{L}$ chloride can be withdrawn (h) if the scavenger well (c) simultaneously withdraws $54 \mathrm{gal} / \mathrm{min}$.

The family of curves that describes the increase in chloride concentration with pumping rates of the production and scavenger wells probably remains basically the same, regardless of the location of the intake of the scavenger well. The asymptotes would be the same, although the approach to the asymptotes might differ. For example, if the scavengerwell intake were to be placed somewhat higher than 130 feet, it follows that the curves generated would be more gradual and the asymptote would be reached somewhat later.

\section{APPLICATION OF DESIGN TO OTHER WELLS AND AQUIFERS}

Five important assumptions must be made in order to use the methods described herein to design scavenger/ production well couples for other wells. The assumptions pertain to aquifers that exhibit radial flow when stressed by pumping from a well, and they pertain to wells that are 100 percent efficient or, at least, maintain the same efficiency over a wide range of withdrawal rates.

First, equilibrium conditions in an aquifer under constant pumping are developed in terms of the upward movement of saltwater and the corresponding stabilization of chloride concentration. Depending on the vertical distribution of horizontal hydraulic conductivity of the aquifer materials open to the well-screen interval, equilibrium conditions could develop within minutes after start of pumping or could require hours or days to be achieved if the differences in fluid properties (density and dynamic viscosity) between the saltwater and the freshwater are greater.

Second, the placement of the intakes of the scavenger and production wells is not particularly critical if the production well is placed in the upper part of the freshwater section and the scavenger well is in the upper part of the saltwater section of the well profile. The placement becomes more critical as the well diameter decreases, transmissivities decrease, or pumpage rates increase.

Third, depending on the distribution of saltwater, freshwater, and transverse (horizontal) hydraulic conductivity within the aquifer, the chloride load of the pumping well develops a linear relation to the pumping rate and reflects the movement of saltwater (or freshwater) toward more conductive parts of the aquifer. Saltwater actually replaces 
freshwater in the lower part of the freshwater zone in the aquifer near the pumping well.

Fourth, the total chloride load produced from a well at a particular pumping rate represents the sum of the chloride loads and pumping rates when the scavenger well and the production well pump simultaneously from the same well, regardless of the placement of the two pump intakes.

Fifth, a maximum chloride concentration is reached by the scavenger well as the pumping rate of the production well is increased. The chloride concentration becomes constant and equal at all scavenger-well pumping rates and represents the chloride concentration of the saltwater intercepted while moving toward the production well.

The hydraulic analysis described herein can be applied to any well that has radial flow and that exhibits increasing chloride at increasing rates of pumping. The hydraulic response of an aquifer to a pumping well will vary considerably because of vertical variations in hydraulic conductivity and saltwater distribution within the aquifer, screen location, and pumping rate. However, if freshwater occurs as a thin layer above saltwater in an aquifer, a well can be developed by using the following scavenger-production wellcouple procedure.
1. Obtain a profile of specific conductance with depth to identify where freshwater and saltwater occur in the borehole. Two profiles are ideal: one before any withdrawals are made from the well, and another while the well is pumped.

2. Position the screen of the production well and scavenger well within the well bore open to the aquifer near the top of the freshwater zone and near the top of the saltwater zone, respectively. Pump them simultaneously at various rates to provide a range of chlorideload data sufficient to establish chloride-load-curve asymptotes for both the scavenger and production wells as shown in figure 11 . Try to keep the scavenger well at a constant pumping rate and vary the production well rate so that the asymptotes of the relation become apparent. The pumping rates selected need to be consistent with the yield capabilities of the aquifer and the well. In general, nonpumping periods between changes in pumping rate of the production well should be used to allow the prepumping condition of vertical distribution of specific conductance to return to water in the borehole. If freshwater parts of the aquifer are highly transmissive and respond quickly to changes in pump-

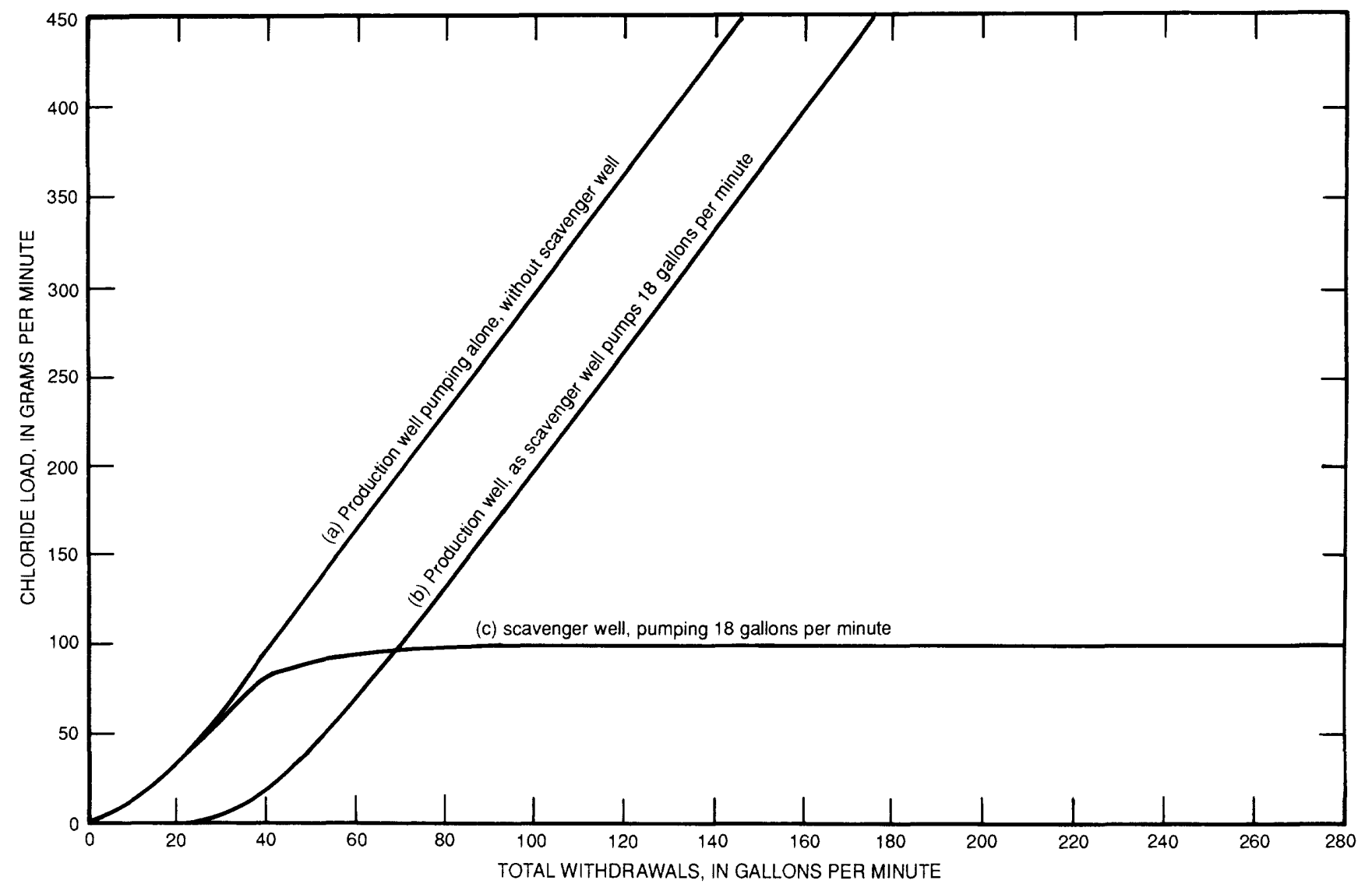

Figure 11. Chloride load of water withdrawn from La Trocha production well pumping at various rates while scavenger well pumps simultaneously at 0 or 18 gallons per minute. 
ing in terms of reaching stabilized chloride concentrations, the pumping rates can be varied without using nonpumping intervals, and stabilized values of chloride load obtained would be nearly the same as if nonpumping intervals had been provided.

3. Plot the curves that describe the relations between chloride loads and pumping rates for the scavenger and production wells, in a manner similar to that in figure 12 , and superposition them on a chloride-load curve representative of withdrawals from a well using only one pump. Align the chloride-load curve asymptotes parallel to the single-pump chloride-load curve (as in fig. 12), but offset them according to the quantity of saltwater pumped by the scavenger well. Finally, convert the chlorideload curves to chloride-concentration curves similar to those in figure 13 to facilitate selection of required pumping rates for selected well yields having desired chloride concentration.

\section{SUMMARY AND CONCLUSIONS}

Aquifers in coastal areas of Puerto Rico commonly contain limited quantities of freshwater that occur as a thin layer above saltwater in the water table. Many wells have been abandoned because they were inadvertently screened in saltwater parts of the aquifer.

Scavenger/production well couples installed in wells, screened in both freshwater and saltwater parts of the aquifer, provide an effective method for producing freshwater from the upper part of the well while withdrawing saltwater from the lower part. Withdrawal of a sufficient quantity of lowchloride water by use of the well couple depends on how the saltwater moves upward in the aquifer when the well couple is pumped. Upward movement of saltwater depends on the relative concentrations of chloride in the well and on the distribution of horizontal and vertical hydraulic conductivity of the aquifer.

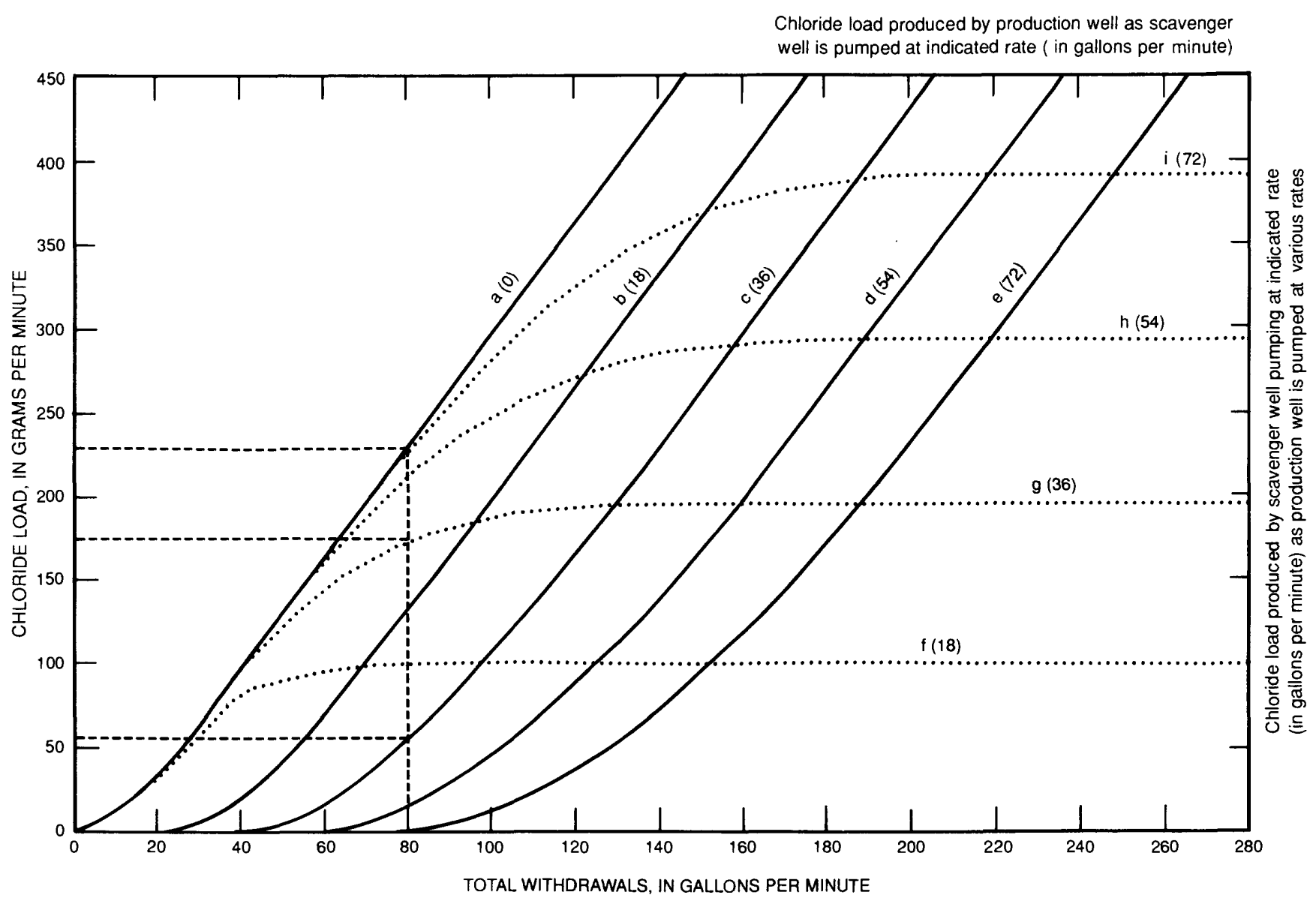

Figure 12. Chloride load of water withdrawn from La Trocha production well (solid lines, a-e) and scavenger well (dotted lines, $\mathrm{f}-\mathrm{i})$ pumping simultaneously. Pumping rates for scavenger well are constant while those for production well vary. Dashed lines discussed in text. 


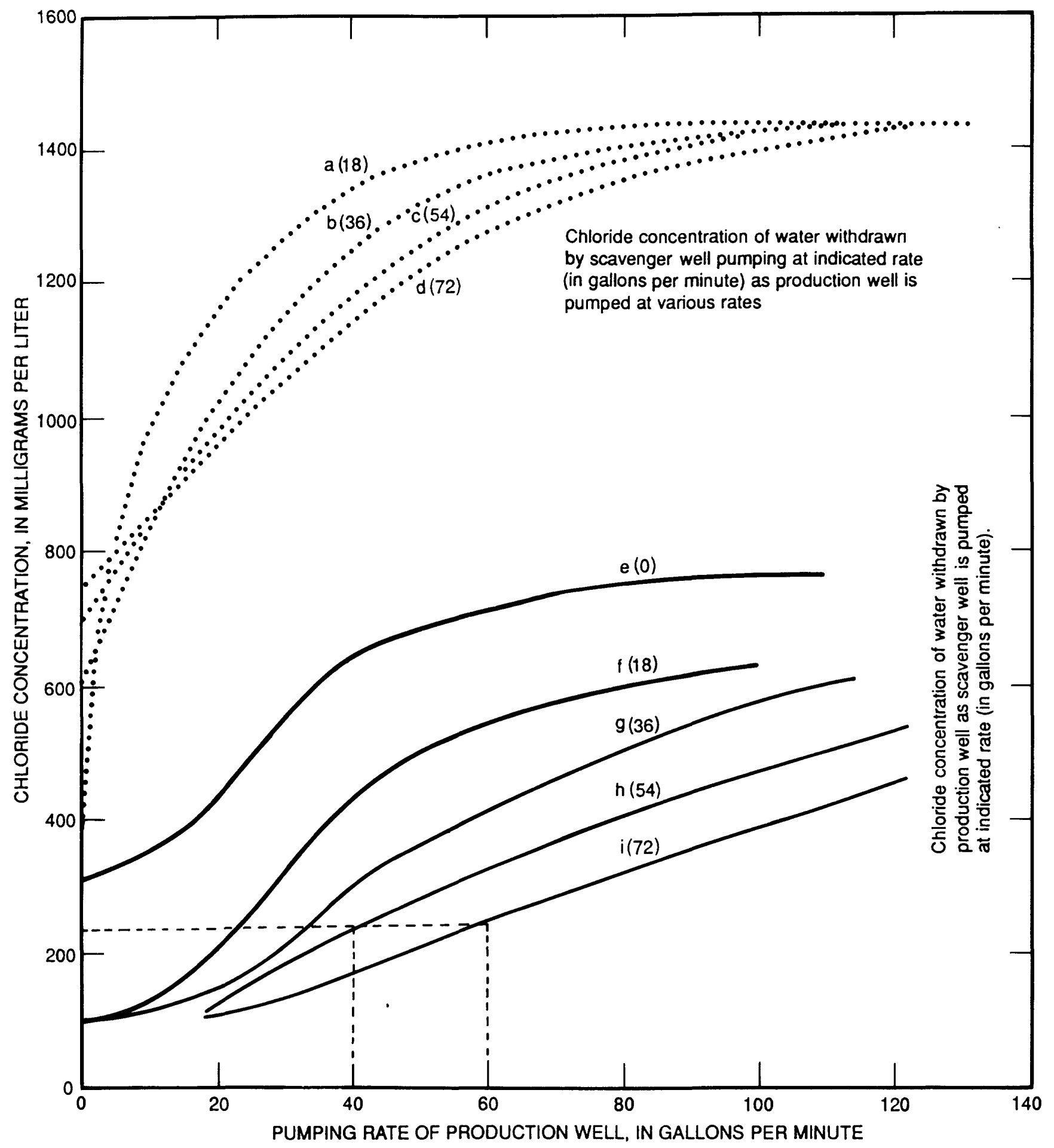

Figure 13. Chloride concentration of water withdrawn from La Trocha production well (solid lines, e-i) and scavenger well (dotted lines, a-d) pumping simultaneously. Pumping rates for scavenger well are constant (in gallons per minute) while those for production well vary. Dashed lines discussed in text. 
For any well screened in an aquifer that contains both freshwater and saltwater, a family of curves can be constructed to represent all combinations of pumping rates and corresponding chloride loads produced when the scavenger well and the production well are pumping simultaneously.

The curves permit the optimization of freshwater withdrawals on the basis of desired pumping rates and the levels of chloride concentration of water required for each well. The scavenger-production well technique can be applied to any well that exhibits radial flow and that maintains a stable well efficiency over a wide range of pumping rates.

\section{SELECTED REFERENCES}

Guisti, E.V., and Bennett, G.D., 1976, Water resources of the northcoast limestone area, Puerto Rico: U.S. Geological Survey Water-Resources Investigations Report 75-42, 47 p.

Long, R.A., 1965, Feasibility of scavenger-well system as a solution to the problem of vertical salt-water encroachment: Louisiana Department of Conservation and Louisiana Department of Public Works, Water Resources Pamphlet 15, 27 p. Rushton, K.R., and Howard, K.W.F., 1982, The unreliability of open observation boreholes in unconfined aquifer pumping tests: Ground Water, v. 20, no. 5, p. 546-550. 